\title{
DOES THE TECHNOLOGY PORTRAYED IN TELEVISION CRIME SHOWS HAVE AN EFFECT ON POTENTIAL JURORS?
}

\author{
Gary A. Davis, Robert Morris University, davis@rmu.edu \\ Karen L. Paullet, Robert Morris University, paullet@rmu.edu \\ Max Houck, West Virginia University, max.houck@mail.wvu.edu \\ Tom Swan, Allegheny County District Attorney's Office, tswan@da.allegheny.pa.us
}

\begin{abstract}
The CSI-Effect (Crime Scene Investigation Effect) proposes that jurors tend to acquit suspects when forensic evidence doesn't exist (or when existing technology fails to reveal sufficient forensic evidence). This study surveyed 71 students in Computer and Information Systems-related degree programs. Specifically, the survey attempted to answer two questions: 1) Does the technology portrayed in CSI-type(i.e., forensically-oriented) television shows increase viewers' knowledge of forensic evidence?, and 2) Does the technology portrayed in CSI-type television shows influence the way a juror will decide a case? The study found that, while an abundance of anecdotal evidence supports the CSI-Effect, statistically significant conclusions continue to elude researchers in this field.
\end{abstract}

Keywords: CSI-Effect, Computer Forensics, Network Forensics, Digital Forensics, Information Security

\section{INTRODUCTION}

The "CSI-Effect" is a term that has been coined by the media to describe the potential impact that CSI (Crime Scene Investigation) -type television shows-which depict forensic science as a major part of the fictional investigations-have on jurors in the U.S. criminal justice system. Some authors have argued that jurors who watch television crime shows tend not to convict suspects because procedures and forensic technology observed from the shows were not applied to the case [4]. However, the actual impact (if any) of the CSIEffect on the outcome of court trials continues to be a topic of much dispute. In a 2006 article, Houck underscores the need for a conclusive, quantitative study of the CSI-Effect: "Whether the CSI-Effect truly exists as a quantifiable influence on courtroom behavior is still a subject of debate" [5].
Since the late 1990's, television crime shows such as Law and Order, CSI, and NCIS (Naval Criminal Investigative Service) have portrayed forensic science as a tool that provides quick and absolute answers to help solve crimes. It has been hypothesized that the forensic technology depicted in television crime shows can raise jurors' expectations of what criminal science can actually deliver in the courtroom. More specifically, jurors who watch television crime shows may have a heightened expectation of how "high-tech" science can assist in solving cases. In such a scenario, evidence that is offered during a trial often disappoints jurors because there is little or no "forensic evidence" presented; compared to what is seen on television. One of the many definitions of the CSI-Effect theorizes that "jurors are acquitting more defendants because in court they are not seeing enough forensic science to persuade them of guilt" [10].

The most popular television crime shows focus on the use of science and technology in solving crimes [12]. The interest in solving crimes is not a new phenomenon: people have a natural attraction and interest in restoring order. The first known murder novel The Rector of Veilbye was written by Steen Steenser Blicher in 1829. The book was based on a true murder that took place in the 1600 's. Several years later in 1841, Edgar Allen Poe wrote his first murder mystery, The Murders of the Rue Morgue. Prior to television crime shows such as CSI, NCIS, and Cold Case Files, people were drawn to books, articles, movies and games that were based on solving crimes. As simplistic as it may be, even the cartoon Scooby Doo (HannaBarbera Productions) was based on solving mysteries. Scooby Doo has caught the attention of young and old viewers for over 40 years. Even the vehicle driven by Scooby and the gang is called the "Mystery Machine." Over the years, one of the best selling games of all time is Clue (Parker Brothers/Hasbro Games). In Clue, players assume the role of fictional characters (e.g., Colonel 
Mustard, Professor Plum, or Miss Scarlet) and try to solve a murder case.

Before DNA was implemented in 1987, television crime shows such as Charlie's Angels, Heart to Heart, and Columbo, were based on clues found at a crime scene. In 1984, however, Sir Alec Jeffreys discovered DNA (Deoxyribonucleic Acid). DNA is also known as "genetic fingerprinting." As Jeffreys worked on the gene codes for protein, he realized that part of the gene consisted of short sequences that repeated a number of times. The number of repetitions varied among individuals as a unique identifier that acted like a fingerprint. This DNA "fingerprinting" assists in resolving issues of identity and kinship; thus creating the field of Forensic DNA. The impact of DNA to help resolve paternity issues, catching criminals and freeing the innocent has affected people worldwide [14]. This method of testing has sparked television networks to create shows around this new science. The conclusive DNA testing depicted on a television crime show provides certainty to the viewers that the real criminal has been caught and punished [16]. DNA has also become the iconic method of biological identity in forensic cases, paternity testing, and other biometric functions [1].

The CSI-Effect may have a positive aspect. The same television crime shows that can distort modern investigative techniques have also sparked an interest in the criminal justice system. Universities and colleges now offer degrees in forensic science and forensic-related fields (e.g., forensic accounting, computer forensics, network forensics, and forensic photography, et al.) in order to appease this new interest. Enrollment in accredited programs is on the rise, particularly in the sciences [6]. The problems with this newfound awareness of the criminal justice system often centers on unrealistic expectations of what forensic science can deliver. This new enthusiasm by college students is based partially on technology used on television crime shows that is often experimental or non-existent [4]. In reality, cases can take 12 months or longer to actually make it to trial. Real forensic scientists rarely gather and collect evidence from a crime scene; instead, trained police officers or evidence technicians actually collect the evidence and then turn the evidence over to the forensic laboratory to be analyzed. On television, tests are completed within minutes. In reality, with existing technology, it can take up to weeks for a test result. On television, the forensic evidence is conclusive and the perpetrator often confesses; so no trial may be depicted. In reality, most court cases do not hinge entirely on forensic evidence. In contrast, forensic evidence simply provides further validation and support for a jury to deliver a guilty verdict.

\section{RESEARCH QUESTIONS}

The current study attempted to gather and analyze quantitative data concerning the CSI-Effect. Specifically, the current study examined the following research questions concerning the CSIEffect:

1. Do potential jurors who watch television crime shows have an increased knowledge of forensic evidence, as compared to potential jurors who do not watch crime shows?

2. Are potential jurors who watch television crime shows more likely to acquit (i.e., find not-guilty) a suspect, as compared to potential jurors who do not watch crime shows?

\section{RELATED RESEARCH}

As mentioned previously, the term "CSI-Effect" has been coined by the media to describe the potential impact that television crime shows might have on the U.S. criminal justice system. In past research studies, however, the operational definition of this term has endured much debate. Some previous researchers have presented as many as six separate and distinct definitions as to what constitutes the "CSI-Effect" [3]. In her research, Podlas defined the CSI-Effect from three separate perspectives: 1) CSI-type television shows create "unreasonable expectations on the part of jurors, making it more difficult for prosecutors to obtain conviction," 2) CSI-type television shows raise the status of forensic evidence to "virtual infallibility," which can actually help prosecutors obtain a conviction, and 3) CSI-type television shows generate interest in forensic science among high school and college students [9].

Past research studies have typically focused on the first definition of the CSI-Effect from Podlas (i.e., that television crime shows raise the expectations of jurors and make it more difficult for prosecutors to obtain a conviction). For example, A.P. Thomas surveyed 102 prosecutors and concluded 
that the prosecutors perceive the CSI-Effect to exist [14]. Of the prosecutors who were surveyed in the study, $38 \%$ believed that they had a trial that resulted in an acquittal or "hung" jury (i.e., a jury that is "deadlocked" and cannot reach a verdict) because forensic evidence was not available. The study recognized that is it common (after a verdict has been delivered) for attorneys to survey jurors on how the jurors came to their decision. Approximately $40 \%$ of prosecutors surveyed in the 2005 study were asked questions by jurors regarding DNA, latent fingerprints, trace evidence, and ballistics; even though the terms had not been used in the trial. In the study, $70 \%$ of prosecutors asked potential jurors if the juror's understanding of the legal system was based on television crime shows. Prosecutors in the study also observed that jurors want fingerprints or some type of forensic evidence to help convict the suspect; even when the suspect confessed to committing the crime. Finally, the study revealed that $68 \%$ percent of prosecutors believed that defense attorneys play on the perceptions created by television crime shows to help win cases [14].

In 2008, G. Thomas conducted an expanded study on the CSI-Effect that included 455 law enforcement agencies in North Carolina [15]. Out of the 264 (58\% response rate) agencies that responded to the survey, a large majority $(74.6 \%)$ agreed that CSI-type television shows are changing the way law enforcement collects evidence and conducts investigations. The results of this recent study show that "... the law enforcement respondents overwhelmingly claim that their agency has changed their law enforcement practices to overcome a perceived CSI effect" [15].

Not all research studies support the existence of a CSI-Effect. Schweitzer and Saks for example, surveyed 48 university students to determine if watching television crime shows had a marked impact on how a potential juror might decide in a case [10]. In this study, the researchers presented the 48 subjects with a courtroom transcript from a hypothetical criminal trial. The simulated trial involved a hair sample that was left at the crime scene by the suspect. The transcript also contained simulated "testimony" that would be typical from a hair identification expert. After reading the transcript, subjects were asked how they would decide if they were serving on a jury for the case. The results of the study revealed that there was no statistically significant difference in conviction rates between subjects who reported watching television crime shows and subjects who did not watch such shows. The study revealed, however, that viewers of such shows did expect more forensic science to be available in court cases: “. . - people who watch such television programs regularly expect better science than what they are often presented with in courts" [10].

Another study conducted in 2007 surveyed 1,027 people who had been called for jury duty. In this study, researchers Kim, Barak, and Shelton examined the jurors' television viewing habits and the jurors' expectations that forensic evidence would be introduced during the course of the trial [8]. Similar to the Schweitzer and Saks study, this study also found that jurors had increased expectations regarding forensic evidence. Unlike the Scheitzer and Saks study, however, the Kim, et al. study did not find a link between the viewing of television crime shows and the heightened expectations regarding forensic evidence. Rather, the authors attributed the heightened expectations for forensic evidence to a growing "Tech-Effect" in our society. Under the Tech-Effect theory, jurors serving in our criminal justice system would have heightened expectations of forensic science simply because technology is so prevalent within our society. Supporters of the Tech-Effect would, therefore, propose that the technology portrayed on television crime shows is simply a reflection of the technology that is rampant in our society.

Clearly, additional quantitative research is needed to further explore the CSI-Effect. This subsequent research must determine if the CSI-Effect truly exists in our criminal justice system or if the knowledge and expectations of jurors is simply a reflection of our digital nation.

\section{METHODS AND PROCEDURES}

\section{Approach and Sample}

The research involved the administration of a survey instrument to 71 undergraduate, graduate, and post-graduate students enrolled in CIS (Computer and Information Systems) -related degree programs. The survey was administered online to students in the following undergraduate and graduate courses: Systems Analysis and Design, Project Management, Ethical Issues in Computing (undergraduate), Computer Forensics, 
Cyberlaw, and Competitive / Business Intelligence Systems (graduate). Students completed the online survey on their own time and submitted their anonymous results directly into an electronic database for analysis.

A quantitative methodology was selected for this research as a means to examine the effect of television crime shows on potential jurors. The population chosen for the survey was comprised of undergraduate and graduate students at a MidAtlantic University who were 18 years of age or older. The survey was administered using Vovici Feedback, an online survey tool. The survey link was active from March 20, 2010 through April 7, 2010. The subjects consisted of resident and nonresident students.

The survey instrument used in the current research was based on a similar research survey developed by Campbell [2]. Anecdotal accounts of the CSIEffect were represented in the survey by creating additional data collection variables. In addition, Deputy District Attorney Tom Swan from the Allegheny County District Attorney's Office created crime scenarios based on real cases in the criminal justice system. Survey questions were then developed from the crime scenarios.

The survey results were analyzed using SPSS (Statistical Package for the Social Sciences) statistical software. This study used the Pearson Chi-Square and the Paired-Samples T-Test to determine if the technology portrayed in television crime shows impacts a potential juror's decision in a criminal case. Statistical frequencies were used to determine the difference between subjects who watched large amounts of television crime shows (i.e., four or more hours), and those subjects who watched small amounts of television crimes shows (i.e., less than four hours per week). The fourhour threshold was used because it divided the sample into two groups of approximately equal size (i.e., 34 and 37, respectively).

\section{Survey Instrument}

The survey instrument was designed to measure two things: 1) the subjects' knowledge regarding forensic evidence, and 2) the subjects' tendency to acquit a suspect (i.e., find "not-guilty"). The survey also asked subjects to report the number of hours per week that they watched television and the number of hours per week that they watched television crime shows. The number of hours watched per week of crime shows was used to divide the subjects into groups for comparison.

The survey instrument consisted of 33 closedended questions and three open-ended questions. The first three questions addressed the participants' television viewing habits. Questions four through ten solicited demographic information from the subjects, such as age-range, gender, and enrolled degree program. Questions 11 through 19 were developed based on the subjects' knowledge of the criminal justice system. In order to answer questions 20 - 36, the subjects were given instructions to respond as if they had been selected to serve on a jury in criminal court. Specifically, the subjects were asked to read each crime scenario and respond as if they were sitting on a jury that was assigned to the case. Subjects were to use their current knowledge of U.S. law and the U.S. criminal justice system.

\section{RESULTS}

\section{Knowledge of Forensic Technology}

In order to address the first research question (i.e., do potential jurors who watch television crime shows have an increased knowledge of forensic evidence, as compared to potential jurors who do not watch crime shows?), the survey asked specific questions designed to gauge the subjects' knowledge of forensic evidence. In particular, the survey asked the following questions concerning forensic knowledge: 1) Do all bodily fluids fluoresce (glow)?, 2) Are a deceased victim's hands bagged in plastic?, 3) Are latent prints visible?, and 4) Can fingerprints be retrieved from any surface at a crime scene? The results from the responses to these questions are summarized in APPENDIX A - Tables 1 through 4.

The Pearson Chi-Square was used to determine the statistical significance of any existing difference between those subjects who watched large amounts of television crime shows and those who watched small amounts of television crime shows. As explained in the METHODS AND PROCEDURES section, large amounts of television crime shows were defined as watching four or more hours of such shows per week; small amounts were defined as watching less than four hours of such shows per week. 
As presented in Table 1, the subjects who watched large amounts of crime shows were less likely $(n=$ 23) to answer "No" (i.e., "No" being the correct response) to the question "Do all body fluids glow?" Conversely, those subjects who watched small amounts of crime shows were more likely ( $n$ $=26$ ) to answer the same question correctly. Even though this question suggests that watching more hours of crime shows does not increase one's forensic knowledge, the difference was not statistically significant at the .05 confidence threshold $\left(x^{2}=.057, p=.811\right)$.

The results from the second knowledge question (i.e., "Are a deceased victim's hands bagged in plastic?), are summarized in APPENDIX A, Table 2. Once again, as noted in Table 2, the subjects who watched large amounts of crime shows were less likely $(n=22)$ to answer "No" (i.e., "No" being the correct response) to this question. Subjects who watched small amounts of crime shows were more likely to answer this question correctly $(n=27)$. Once again, it would seem that watching crime shows does not increase one's forensic knowledge; however, the noted difference was not statistically significant $\left(x^{2}=.566, p=\right.$ $.452)$.

The next two forensic knowledge questions in the survey concerned fingerprinting technology. Specifically, the third forensic knowledge question asked subjects "Are latent fingerprints visible?" Subjects who watched large amounts of crime shows tended to answer correctly $(n=22)$ for this question (i.e., "No" being the correct response). Subjects who did not watch large amounts of crime shows did not fare as well on this question $(n=18)$. Even though watching crime shows seemed to increase subjects' knowledge regarding this fingerprinting question, the difference was not statistically significant $\left(x^{2}=1.857, p=.173\right)$. These results are summarized in APPENDIX A, Table 3.

The last forensic knowledge question also dealt with fingerprinting technology, "Can a fingerprint be retrieved from any surface at a crime scene?" As in the last question, subjects who watched large amounts of crime shows did better than those who did not watch large amounts of crime shows. Specifically, 14 out of the 34 people who watched large amounts of crime shows answered this question correctly (i.e., "No" being the correct response). Conversely, only seven out of the 37 subjects who did not watch large amounts of crime shows answered correctly. In addition, the difference in responses between the two participant groups was statistically significant $\left(x^{2}=\right.$ 4.214, $p=.040)$. The above results are summarized in APPENDIX A, Table 4.

\section{Impact on Jurors' Decisions}

In order to address the second research question (i.e., Are potential jurors who watch television crime shows more likely to acquit a suspect, as compared to potential jurors who do not watch television crime shows?), the survey asked subjects to read and then respond to various crime scenarios. Subjects were asked to respond as if they were a juror who was assigned to the case in question. In particular, the survey asked subjects to respond to the following three crime scenarios: 1) a burglary case that hinged on modern fingerprinting technology, 2) a drive-by shooting case that hinged on modern surveillance technology, and 3) a murder case that hinged on digital evidence recovered from a computer and from the Internet. The results from the responses to these questions are summarized in APPENDIX B - Tables 5 through 7.

The Paired-Samples T-Test was used to determine the statistical significance of any existing difference between participant groups. As in the prior Chi-Square analysis, subjects were divided into the following groups: 1) those who watched large amounts of television crime shows, and 2) those who watched small amounts of television crime shows. A Likert-like scale was used to solicit subjects' responses concerning the guilt or innocence of the suspects in the crime scenarios. The response scale for each crime scenario ranged from a value of 1 ("I am VERY CONFIDENT that the suspect is guilty") to a value of 6 ("I am VERY CONFIDENT that the suspect is Not Guilty").

Regarding the burglary scenario, subjects who watched large amounts of crime shows demonstrated a higher rate of acquittal (i.e., reported a higher number of "Not Guilty" judgments) than those subjects who watched small amounts of crime shows. The mean rate of acquittal among subjects who watched large amounts of crime shows was 3.24. Alternatively, the mean rate of acquittal among subjects who did not watch large amounts of crime shows was 2.89. In addition, the difference between the participant 
groups approached (but did not quite achieve) statistical significance $(t=1.906, p=.061)$. The responses to the burglary scenario are summarized in APPENDIX B, Table 5.

Reviewing the results from the drive-by shooting scenario, subjects who watched large amounts of crime shows once again reported higher acquittal rates $(\overline{\mathrm{x}}=3.03)$, in contrast to subjects who did not watch large amounts of crime shows $(\overline{\mathrm{x}}=2.73)$. However, unlike the burglary scenario, the difference between participant groups regarding the drive-by shooting scenario did not approach statistical significance $(t=1.155, p=.252)$. The responses to the drive-by shooting scenario are presented in APPENDIX B, Table 6.

The third crime scenario in the survey involved a murder that was planned using computers and the Internet. As in the previous scenarios, subjects were asked to weigh the evidence involved and then cast a decision as to whether the suspect is guilty or should be acquitted. Similar to the burglary scenario and the drive-by shooting scenario, the subjects who watched large amounts of crime shows once again reported high acquittal rates $(\overline{\mathrm{x}}=3.26)$ compared to subjects who did not watch large amounts of crime shows $(\overline{\mathrm{x}}=2.95)$. Consistent with the results from the other crime scenarios, the difference in participant groups regarding the computer-crime scenario were not statistically significant $(t=1.274, p=.207)$. The responses to the computer-crime scenario are summarized in APPENDIX B, Table 7.

\section{CONCLUSIONS}

The present research surveyed undergraduate, graduate and post-graduate students in Computer and Information Systems-related programs to examine the following questions: 1) Do potential jurors who watch television crime shows have an increased knowledge of forensic evidence, as compared to potential jurors who do not watch television crime shows?, and 2) Are potential jurors who watch television crime shows more likely to acquit (i.e., find not-guilty) a suspect, as compared to potential jurors who do not watch television crime shows.

In the current study, four survey questions were analyzed to gauge the subjects' knowledge of forensic evidence. The first two survey questions that were analyzed revealed that those subjects who watched large amounts (>= 4 hours) of television crime shows actually scored worse than those subjects who watched small amounts $(<4$ hours) of the crime shows. The result from the first survey question (i.e., Do all bodily fluids glow?) is not surprising, considering that most television crime shows frequently depict all bodily fluids as fluorescent. The result from the second survey question (i.e., Are a deceased victim's hands bagged in plastic?) is not surprising either, since most crime shows do show victims' hands bagged in plastic. In a real criminal investigation, however, the victim's hands are bagged in paper (rather than plastic) in order to preserve evidence and to prevent condensation.

The second two survey questions that were analyzed revealed that those subjects who watched large amounts ( $>=4$ hours) of television crime shows scored better than those subjects who watched small amounts $(<4$ hours $)$ of the crime shows. The result from the third survey question (i.e., Are latent prints visible?) is not surprising because the actors on television crime shows do demonstrate the proper procedures for dusting and lifting fingerprints. The result from the fourth survey question (i.e., Can fingerprints be retrieved from any surface?) is also not surprising. As in the previous question, television crime shows tend to portray fingerprinting procedures accurately. Specifically, actors in crime dramas are shown retrieving fingerprints only from hard surfaces (i.e., not from porous surfaces, such as fabrics or carpets).

It should be noted, however, that three of the four survey questions discussed above did not show a difference in subject groups that was statistically significant. Although, it would appear that subjects who watched large amounts of crime shows did learn about forensic evidence and procedures; however, those subjects did not learn the proper methods for collecting and analyzing evidence.

In the current study, three crime scenarios were used to determine if subjects who watch large amounts of crime shows tend to decide differently than subjects who watch small amounts of crime shows. Specifically, the current study attempted to discover if subjects who watch large amounts of crime shows tended to acquit suspects at a higher rate than subjects who watch small amounts of the shows. 
The results from all three crime scenarios revealed that those subjects who watched large amounts of crime shows did have higher acquittal rates than those who watched smaller amounts of the shows. However, it should be noted that the results from only one scenario approached statistical significance. Further, none of the results were significant at the .05 threshold.

Although the results of the current study tend to support a relationship between hours of crime shows watched and juror verdict, the results were not statistically significant. These findings are consistent with the results of past studies in which statistical tests did not yield conclusive results. Schweitzer and Saks, for example, found no statistically significant difference in juror verdicts that could be attributed to hours of crime shows watched [10]. In a similar conclusion, Shelton, Kim, and Barak found " . . . that specifically watching CSI or a similar show did not have a causative impact on juror demands for scientific evidence as a condition of a guilty verdict ..." [13].

In addition to examining the CSI-Effect, the current study also raises the following, much broader issue: "Does television reflect society or does society reflect television?" Perhaps, it is difficult in these studies to isolate the "CSI-Effect" from a much larger "Media Effect." The subjects in the current study were divided into those who watched large amounts of crime shows and those who watched small amounts. However, no subject groups were analyzed who watched zero amounts of crime shows. It is possible that watching any amount of crime shows predisposes subjects to certain lines of thinking. As difficult as it may be, future studies might compare subjects who watch crime shows with those subjects who do not.

\section{REFERENCES}

1. Butler, J.M. (2005). Forensic DNA typing: biology and technology behind STR markers. San Diego, CA, Academic Press: Elsevier.

2. Campbell, A. (2006). The phenomenon: what is the CSI effect? Retrieved on January 5, 2010 from www.the-csi-effect.com

3. Cole, S.A., \& Dioso-Villa, R. (2009). Investigating the CSI effect: media and litigation crisis in criminal law. Stanford Law Review, 61 (6), 1335-1374.

Volume XI, No. 1, 2010
4. Heinrick, J. (2006). Everyone's an expert: the csi effect's negative impact on juries. The Triple Helix, 59-61.

5. Houck, M. (2006, July). CSI: reality. Scientific American, 85-89.

6. Jackson, G. (2009). The status of forensic science degree programs in the United States. Forensic Science Policy and Management. 1(1), 2-9.

7. Jeffreys, A. (2004 January) Professor Sir Alec Jeffreys - research work and short biography. University of Leicaster. Retrieved on February 20, 2010 from

http://www2.le.ac.uk/officer/press/mediacentr e/archive/dnafingerprinting/profsirslecjeffreys

8. Kim, Y.S., Barak, G., \& Shelton, D.E. (2009). Examining the "CSI-effect" in the cases of circumstantial evidence and eyewitness testimony: multivariate and path analyses. Journal of Criminal Justice, 37 (5), 452-482.

9. Podlas, K. (2001). Please adjust your signal: wow television's syndicated courtrooms bias our juror citizenry. American Business Law Journal, 39 (1), 1-24.

10. Schweitzer, N.J., \& Saks, M.J. (2007, Spring). The CSI effect: popular fiction about forensic science affects the public's expectations about real forensic science. Jurimetrics, 357-364.

11. Seal, R. (2007, November 25). CSI effect brings unrealistic expectations, lawyers say. McClatchy-Tribune Business News.

12. Shelton, D.E. (2008). The CSI effect: does it really exist? National Institute of Justice Journal (259), 1-7.

13. Sheldon, D.E., Kim, Y.S., \& Barak, G. (2007). A study of juror expectations and demands concerning scientific evidence: does the 'CSI effect' exist? Vanderbilt Journal of Entertainment \& Technology Law. 9.2 331368.

14. Thomas, A.P. (2006). The CSI effect on jurors and judgments. The Yale Law Journal. Pocket Part 70, 115-119.

15. Thomas, G. North Carolina law enforcement officers' perceptions regarding the CSI effect. M.A. dissertation, The University of North Carolina at Greensboro, United States -North Carolina. Retrieved March 18, 2010, from Dissertations \& Theses: A\&I. (Publication No. AAT 1456453).

16. Tyler, T.R. (2006). Viewing CSI and the threshold of guilt: managing truth and justice in reality and fiction. The Yale Law Journal, 115 (5), 1050-1085. 


\section{APPENDIX A - Chi-Square Test Results}

\section{Table 1: Chi-Square Test Results}

Cross tabulation of Hours of Crime Shows and "All body fluids glow?"

\begin{tabular}{lcccc}
\hline & \multicolumn{2}{c}{ Hours of Crime Shows Watched per Week? } & & \\
\cline { 2 - 4 } $\begin{array}{l}\text { All body } \\
\text { fluids glow? }\end{array}$ & $<4$ & $>=4$ & $\chi^{2}$ & Sig. \\
\hline Yes & $\begin{array}{c}11 \\
(-0.2)\end{array}$ & $\begin{array}{c}11 \\
(0.2)\end{array}$ & $.057^{* *}$ & .811 \\
\hline No & 26 & 23 & \\
\hline
\end{tabular}

Note: $* *=p \leq .05$. Adjusted standardized residuals appear in parentheses below group frequencies.

Table 2: Chi-Square Test Results

Cross tabulation of Hours of Crime Shows and "Hands bagged in plastic?"

\begin{tabular}{|c|c|c|c|c|}
\hline \multirow[b]{2}{*}{$\begin{array}{l}\text { Hands bagged } \\
\text { in plastic? }\end{array}$} & \multicolumn{2}{|c|}{ Hours of Crime Shows Watched per Week? } & \multirow[b]{2}{*}{$x^{2}$} & \multirow[b]{2}{*}{ Sig. } \\
\hline & $<4$ & $>=4$ & & \\
\hline Yes & $\begin{array}{c}10 \\
(-0.8)\end{array}$ & $\begin{array}{c}12 \\
(0.8)\end{array}$ & $.566^{\star *}$ & .452 \\
\hline No & $\begin{array}{c}27 \\
(0.8)\end{array}$ & $\begin{array}{c}22 \\
(-0.8)\end{array}$ & & \\
\hline
\end{tabular}

Note: $* *=p \leq .05$. Adjusted standardized residuals appear in parentheses below group frequencies. 
Technology Portrayed in Television Crime Shows

\section{APPENDIX A - Chi-Square Results (continued)}

\section{Table 3: Chi-Square Test Results}

Cross tabulation of Hours of Crime Shows and "Latent prints visible?"

\begin{tabular}{|c|c|c|c|c|}
\hline \multirow[b]{2}{*}{$\begin{array}{l}\text { Latent prints } \\
\text { Visible? }\end{array}$} & \multicolumn{2}{|c|}{ Hours of Crime Shows Watched per Week? } & \multirow[b]{2}{*}{$x^{2}$} & \multirow[b]{2}{*}{ Sig. } \\
\hline & $<4$ & $>=4$ & & \\
\hline Yes & $\begin{array}{c}19 \\
(1.4)\end{array}$ & $\begin{array}{c}12 \\
(-1.4)\end{array}$ & $1.857^{\star *}$ & .173 \\
\hline No & $\begin{array}{c}18 \\
(-1.4)\end{array}$ & $\begin{array}{c}22 \\
(1.4)\end{array}$ & & \\
\hline
\end{tabular}

Note: $* *=p \leq .05$. Adjusted standardized residuals appear in parentheses below group frequencies.

Table 4: Chi-Square Test Results

Cross tabulation of Hours of Crime Shows and "Fingerprint from any surface?"

Hours of Crime Shows Watched per Week?

\begin{tabular}{|c|c|c|c|c|}
\hline $\begin{array}{l}\text { Fingerprint from } \\
\text { any surface? }\end{array}$ & $<4$ & $>=4$ & $x^{2}$ & Sig. \\
\hline Yes & $\begin{array}{c}30 \\
(2.1)\end{array}$ & $\begin{array}{c}20 \\
(-2.1)\end{array}$ & $4.214^{\star \star}$ & .040 \\
\hline No & $\begin{array}{c}7 \\
(-2.1)\end{array}$ & $\begin{array}{c}14 \\
(2.1)\end{array}$ & & \\
\hline
\end{tabular}




\section{APPENDIX B - T-Test Results}

\section{Table 5: T-Test Results}

Paired-Samples T-Test Results of Burglar Suspect Innocent

\begin{tabular}{|c|c|c|c|c|c|}
\hline Pair 1 & Mean & Std. Dev. & t-test & $d f$ & Sig. \\
\hline $\begin{array}{l}\text { Burglar suspect innocent } \\
\text { ( } 1=\text { no confidence; } 6=\text { very } \\
\text { confident })- \text { Hours of Crime } \\
\text { Shows watched }>=4\end{array}$ & 3.24 & .781 & \multirow[b]{2}{*}{$1.906^{* *}$} & \multirow[b]{2}{*}{69} & \multirow[b]{2}{*}{.061} \\
\hline $\begin{array}{l}\text { Burglar suspect innocent } \\
\text { ( } 1=\text { no confidence; } 6=\text { very } \\
\text { confident })- \text { Hours of Crime } \\
\text { Shows watched }<4\end{array}$ & 2.89 & .737 & & & \\
\hline
\end{tabular}

Table 6: T-Test Results

Paired-Samples T-Test Results of Drive-by Suspects Innocent

\begin{tabular}{|c|c|c|c|c|c|}
\hline Pair 2 & Mean & Std. Dev. & t-test & $\mathrm{df}$ & Sig. \\
\hline $\begin{array}{l}\text { Drive-by suspects innocent } \\
\text { ( } 1=\text { no confidence; } 6=\text { very } \\
\text { confident })- \text { Hours of Crime } \\
\text { Shows watched }>=4\end{array}$ & 3.03 & 1.218 & \multirow[b]{2}{*}{$1.155^{\star *}$} & \multirow[b]{2}{*}{69} & \multirow[b]{2}{*}{.252} \\
\hline $\begin{array}{l}\text { Drive-by suspects innocent } \\
(1=\text { no confidence; } 6=\text { very } \\
\text { confident })- \text { Hours of Crime } \\
\text { Shows watched }<4\end{array}$ & 2.73 & .962 & & & \\
\hline
\end{tabular}

Note: $* *=p \leq .05$.

Table 7: T-Test Results

Paired-Samples T-Test Results of Computer Crime Suspect Innocent

\begin{tabular}{|c|c|c|c|c|c|}
\hline Pair 3 & Mean & Std. Dev. & t-test & df & Sig. \\
\hline $\begin{array}{l}\text { Computer Crime suspect innocent } \\
\text { ( } 1=\text { no confidence; } 6=\text { very } \\
\text { confident })- \text { Hours of Crime Shows } \\
\text { watched }>=4\end{array}$ & 3.26 & 1.109 & \multirow[b]{2}{*}{$1.274^{* *}$} & \multirow[b]{2}{*}{69} & \multirow[b]{2}{*}{.207} \\
\hline $\begin{array}{l}\text { Computer Crime suspect innocent } \\
(1=\text { no confidence; } 6=\text { very } \\
\text { confident })- \text { Hours of Crime } \\
\text { Shows watched }<4\end{array}$ & 2.95 & .998 & & & \\
\hline
\end{tabular}

